\title{
Risk Factors for HSV-2 Infection among Sexual Partners of HSV-2/HIV-1 Co-Infected Persons
}

Andrew Mujugira ${ }^{1 *}$, Amalia S Magaret ${ }^{2}$, Jared M Baeten ${ }^{1,3,4}$, Connie Celum,3,4, Jairam Lingappa ${ }^{1,3,5}$

\begin{abstract}
Background: Herpes simplex virus type 2 (HSV-2) is the most frequent cause of genital ulcer disease worldwide and has been associated with increased risk for HIV-1 acquisition and transmission. We conducted a cross-sectional analysis of risk factors for HSV-2 infection among HIV-1 uninfected partners, whose partners were co-infected with HIV-1 and HSV-2.

Methods: Between November 2004 and April 2007, 3408 HIV-discordant couples, in which the HIV-1 infected partners were HSV-2 seropositive with CD4 $250 \mathrm{cell} / \mathrm{s} / \mathrm{mm}^{3}$ or greater, were enrolled in an HSV-2 suppression trial to prevent HIV-1 transmission at 14 sites in 7 African countries. Clinical \& behavioral data, HSV-2 and HIV-1 testing were conducted at enrolment. Univariate and multivariate Poisson regression analyses were performed separately, by gender of the HIV-1 infected partner.

Results: Among 3354 HIV-1 uninfected participants, 32\% were female and overall 71\% were HSV-2 seropositive. Among couples with female HIV-1 infected partners, HIV-1 plasma RNA [aPR 1.03; 95\% Cl: 0.99 to 1.06; $\mathrm{p}=0.11$ ] and CD4 count [aPR 1.00; $95 \% \mathrm{Cl}: 0.98$ to $1.01 ; \mathrm{p}=0.48$ ] in the HSV-2/HIV-1 dually infected female and circumcision in the HIV-1 uninfected male partner [aPR 0.94; $95 \%$ Cl: 0.88 to $1.00 ; p=0.06$ ] were not associated with reduced risk of HSV-2 seropositivity, after adjusting for other factors.

Conclusions: In this cross-sectional analysis of African HIV-1 serodiscordant heterosexual couples with prevalent HSV-2 infection in the HIV-1 infected partner, HIV-1 plasma RNA and CD4 count in the dually-infected partner and male circumcision in the HIV-1 uninfected partner were not associated with HSV-2 concordance.
\end{abstract}

Trial Registration: ClinicalTrials.gov NCT00194519

\section{Background}

Herpes simplex virus type $2(\mathrm{HSV}-2)$ is the most common cause of genital ulcer disease (GUD) worldwide. HSV-2 prevalence in sub-Saharan Africa ranges from $27-57 \%$ in men to $30-74 \%$ in women $[1,2]$ and is higher in HIV-1 infected persons [3]. Epidemiologic studies suggest synergy between HIV-1 and HSV-2 that facilitates the spread of both viruses, with HSV-2 increasing HIV-1 susceptibility and infectiousness [4] and HIV-1 infection increasing HSV-2 reactivation frequency [5].

The increased risk of HIV-1 transmission and acquisition due to HSV-2 infection in the context of an overall high risk of HIV-1 transmission among stable, heterosexual HIV-1 serodiscordant couples (one partner HIV-

\footnotetext{
* Correspondence: mujugira@uw.edu

'Department of Global Health, University of Washington, Seattle, WA, USA

Full list of author information is available at the end of the article
}

1 infected and the other HIV-1 uninfected) [6], which are highly prevalent in Africa [7], make evaluation of risk factors for HSV-2 within HIV-1 serodiscordant couples from diverse parts of Africa of interest.

We conducted a cross-sectional analysis of risk factors for HSV-2 seropositivity in $>3300 \mathrm{HIV}-1$ uninfected members of African HIV-1 serodiscordant couples in which the HIV-1 infected partner was dually-infected with HSV-2. In particular, we sought to assess whether HIV-1 plasma RNA level or CD4 count in the HIV-1 infected partner, as indicators of higher HIV-1 infectiousness and more advanced immunosuppression, modifies HSV-2 infectiousness, and if male circumcision in the HIV-uninfected partners of women with HSV-2/ HIV-1 dual infection protected them from HSV-2 acquisition.

\section{Biomed Central}

C 2011 Mujugira et al; licensee BioMed Central Ltd. This is an open access article distributed under the terms of the Creative Commons Attribution License (http://creativecommons.org/licenses/by/2.0), which permits unrestricted use, distribution, and reproduction in any medium, provided the original work is properly cited. 


\section{Methods}

\section{Study Population}

From November 2004 to April 2007, 3408 heterosexual HIV-1 discordant couples from 14 sites in Botswana, Kenya, Rwanda, South Africa, Tanzania, Uganda and Zambia were enrolled into the Partners in Prevention HSV/HIV Transmission Study, a randomized clinical trial of suppressive acyclovir therapy to reduce sexual HIV-1 transmission from HSV-2/HIV-1 dually-infected women and men to their HIV-1 uninfected partners [7]. HIV-1 discordant couples were eligible for enrolment into the trial if they were sexually active and planning to remain partnered for at least 24 months and if the HIV-1infected participant was HSV-2 infected, had a CD4 count 250 cells $/ \mathrm{mm}^{3}$ or greater, was not on antiretroviral therapy, and was not pregnant. HIV-1 uninfected members of the discordant couples could be either HSV-2 seropositive or seronegative. Clinical and behavioral data collected at study enrolment were used for this analysis.

\section{Laboratory Methods}

HIV-1 testing was done using 2 rapid assays in parallel, most commonly Determine HIV-1/2 (Abbott Diagnostics), Uni-Gold HIV-1 (Trinity Biotech), or Capillus HIV-1/HIV-2 (Trinity Biotech) and paired positive rapid assay results were confirmed by HIV-1 EIA [7]. At all study sites, HSV-2 serostatus was determined using HerpeSelect HSV-2 gG2-based EIA (Focus Technologies). Given the results of previous studies using this assay in African cohorts, a cut-off value of $\geq 3.5$ was chosen to define seropositivity, in order to improve test specificity [8-10]. CD4 quantification was performed for HIV-1 infected participants at 6-month intervals using standard flow cytometry. Plasma HIV-1 RNA was quantified using the COBAS Ampliprep/COBAS TaqMan real-time HIV-1 RNA assay, version 1.0 (Roche Diagnostics, Indianapolis, IN). All HIV-1 and HSV-2 serologic results were confirmed by Western blot, performed at the University of Washington [11].

\section{Statistical Analysis}

Data were entered onto standard case report forms and faxed to a central database at the University of Washington. Analysis was done using SAS version 9.1 (SAS Institute, Cary, NC). Univariate and multivariate analyses were performed using Poisson regression with HSV-2 status of the partner participant as the outcome variable. In order to examine male circumcision and to allow for other possible gender differences in transmission risk, separate analyses were performed for male and female HIV-1 infected participants. Backward elimination, starting with all variables significant at $\mathrm{p}<0.1$ in univariate regression, was performed to select a final multivariate model.

\section{Ethical Approval}

Institutional review boards at the University of Washington and at all collaborating site organizations approved study procedures. All participants provided written informed consent. The trial was registered through ClinicalTrials.gov (NCT00194519).

\section{Results}

\section{Characteristics of study population}

Of 3408 enrolled HIV-1-uninfected participants, 3354 were eligible for this analysis (54 were excluded because either they or their partner were ineligible for the study, based on confirmatory HIV-1 or HSV-2 testing). HIV-1 seronegative partners had a median age of 35 years and 1084 (32\%) were female. Couples reported a median of 4 sex acts in the month prior to enrollment (IQR 2-8). The seroprevalence of HSV-2 among HIV-1 seronegative partners was $71 \%$ overall; $63 \%$ in men versus $89 \%$ in women $(\mathrm{p}<0.001)$. By study design, all HIV-1 infected partners were co-infected with HSV-2. Median CD4 count among HIV-1 infected partners was 462 cells/ $\mathrm{mm}^{3}$ (IQR 347-631) and median plasma HIV-1 RNA was $4.1 \log _{10}$ copies/mL (IQR 3.3-4.7).

\section{Risk factors for HSV-2 infection among HIV-1 uninfected partners}

Among male HIV-1 uninfected partners of HIV-1/HSV2 dually infected females, older age (adjusted prevalence ratio [aPR] 1.11, p < 0.001), a greater number of children (aPR 1.02 per 1 child increase, $\mathrm{p}<0.001$ ) and greater number of years living together ( $\mathrm{aPR} 1.07$, per 1 year increase, $\mathrm{p}=0.009$ ) were significantly associated with HSV-2 infection (Table 1). Characteristics of the female HIV-1 infected partner associated with HSV-2 infection in their male $\mathrm{HIV}-1$ uninfected partners included having herpetic lesions observed on genital exam at enrollment ( $\mathrm{aPR} 0.92, \mathrm{p}=0.04)$, other sexual partners $(\mathrm{aPR} 1.28, \mathrm{p}=0.05)$, and using vaginal drying agents (aPR 1.08, p = 0.05). Circumcised HIV-1 uninfected men were at slightly decreased risk for HSV-2 (aPR 0.94, p = 0.06), although this did not achieve statistical significance.

Among female HIV-1 uninfected partners of HIV-1/ HSV-2 dually-infected males, only older age (aPR 1.08, $\mathrm{p}<0.0001)$ and greater number of years of education (aPR 0.90, p = 0.001) of the HIV-1 infected partner were associated with HSV-2 seropositivity.

Notably, neither HIV-1 plasma RNA level [aPR 1.03; 95\% CI: 0.99 to $1.06 ; \mathrm{p}=0.11$ ] nor CD4 count [aPR 1.00; $95 \% \mathrm{CI}: 0.98$ to $1.01 ; \mathrm{p}=0.48$ ], factors that might indicate increased HSV-2 infectiousness [12], were associated with increased risk of HSV-2 infection in HIV-1 uninfected partners. 
Table 1 Population characteristics and risk factors for HSV-2 seropositivity among HIV-1 uninfected members of African HIV-1 serodiscordant partnerships HIV-1 uninfected female partners of males dually-infected with HSV-2 HIV-1 uninfected male partners of females dually-infected with HSVand HIV-1 ( $\mathrm{N}=1084) \quad 2$ and HIV-1 ( $=2270)$

\begin{tabular}{|c|c|c|c|c|c|c|c|c|c|c|c|c|}
\hline & \multicolumn{6}{|c|}{ and HIV-1 ( $\mathrm{N}=1084)$} & \multicolumn{6}{|c|}{2 and HIV-1 $(\mathrm{N}=2270)$} \\
\hline & $\begin{array}{c}\text { HSV-2 } \\
\text { negative } \\
(\mathrm{n}=123) \\
\#(\%) \text { or } \\
\text { median (IQR) }\end{array}$ & $\begin{array}{c}\text { HSV-2 } \\
\text { positive } \\
(\mathrm{n}=961) \\
\#(\%) \text { or } \\
\text { median (IQR) }\end{array}$ & $\begin{array}{c}\text { Prevalence } \\
\text { ratio } \\
(95 \% \mathrm{Cl})\end{array}$ & $\begin{array}{c}\mathrm{p}- \\
\text { value }\end{array}$ & $\begin{array}{c}\text { Adjusted } \\
\text { Prevalence } \\
\text { Ratio" } \\
(95 \% \mathrm{Cl})\end{array}$ & $\begin{array}{c}\mathrm{p}- \\
\text { value }\end{array}$ & $\begin{array}{c}\text { HSV-2 } \\
\text { negative } \\
(\mathrm{n}=841) \\
\#(\%) \text { or } \\
\text { median (IQR) }\end{array}$ & $\begin{array}{c}\text { HSV-2 } \\
\text { positive } \\
(\mathrm{n}=1429) \\
\#(\%) \text { or } \\
\text { median (IQR) }\end{array}$ & $\begin{array}{c}\text { Prevalence } \\
\text { ratio } \\
(95 \% \mathrm{Cl})\end{array}$ & $\begin{array}{c}\mathrm{p}- \\
\text { value }\end{array}$ & $\begin{array}{l}\text { Adjusted } \\
\text { Prevalence } \\
\text { ratio }^{\#} \\
(95 \% \mathrm{Cl})\end{array}$ & $\begin{array}{c}\mathrm{p}- \\
\text { value }\end{array}$ \\
\hline \multicolumn{13}{|l|}{$\begin{array}{l}\text { Characteristics of HIV-1/HSV-2 } \\
\text { dually-infected partner }\end{array}$} \\
\hline Genital lesions at enrollment & $27(22 \%)$ & $233(24.2 \%)$ & $\begin{array}{c}1.01 \\
(0.97,1.07)\end{array}$ & 0.6 & & & $202(24 \%)$ & $287(20.1 \%)$ & $\begin{array}{c}0.92 \\
(0.85,0.99)\end{array}$ & 0.028 & $\begin{array}{c}0.92 \\
(0.85,0.99)\end{array}$ & 0.04 \\
\hline CD4 count & $424(335-566)$ & $\begin{array}{c}424 \\
(333-571)\end{array}$ & $\begin{array}{c}1.00 \\
(0.99,1.01)^{*}\end{array}$ & 0.66 & & & $\begin{array}{c}484 \\
(358-669)\end{array}$ & $\begin{array}{c}482 \\
(354-659) \\
\end{array}$ & $\begin{array}{c}1.00 \\
(0.98,1.01)^{*}\end{array}$ & 0.48 & & \\
\hline Plasma HIV-1 RNA & $\begin{array}{c}4.35 \\
(3.71-4.95)\end{array}$ & $\begin{array}{c}4.32 \\
(3.67-4.87)\end{array}$ & $\begin{array}{c}0.99 \\
(0.97,1.02)\end{array}$ & 0.64 & & & $\begin{array}{c}3.92 \\
(3.13-4.50)\end{array}$ & $\begin{array}{c}3.96 \\
(3.25-4.55)\end{array}$ & $\begin{array}{c}1.03 \\
(0.99,1.06)\end{array}$ & 0.11 & & \\
\hline Has any other sexual partners & $9(7.3 \%)$ & $78(8.1 \%)$ & $\begin{array}{c}1.01 \\
(0.94,1.09)\end{array}$ & 0.76 & & & $7(0.8 \%)$ & $26(1.8 \%)$ & $\begin{array}{c}1.26 \\
(0.99,1.59)\end{array}$ & 0.058 & $\begin{array}{c}1.28 \\
(1.00,1.63)\end{array}$ & 0.047 \\
\hline \multicolumn{13}{|l|}{$\begin{array}{l}\text { Characteristics of HIV-1 uninfected } \\
\text { partner }\end{array}$} \\
\hline Age & $26(22-30)$ & $31(26-39)$ & $\begin{array}{c}1.09 \\
(1.06,1.12)^{+}\end{array}$ & $<.001$ & $\begin{array}{c}1.08 \\
(1.06,1.11)^{\dagger}\end{array}$ & $<.001$ & $32(28-39)$ & $37(31-44)$ & $\begin{array}{c}1.17 \\
(1.14,1.21)^{+}\end{array}$ & $<.001$ & $\begin{array}{c}1.11 \\
(1.06,1.15)\end{array}$ & $<.001$ \\
\hline Years of education & $8(7-12)$ & $8(6-10)$ & $\begin{array}{c}0.88 \\
(0.83,0.93)^{\dagger}\end{array}$ & $<.0001$ & $\begin{array}{c}0.90 \\
(0.85,0.96)^{\dagger}\end{array}$ & 0.0011 & $9(7-12)$ & $9(7-12)$ & $\begin{array}{c}0.89 \\
(0.82,0.97)^{\dagger}\end{array}$ & 0.01 & $!$ & \\
\hline Has any other sexual partners & $1(1.5 \%)$ & $4(0.8 \%)$ & $\begin{array}{c}0.91 \\
(0.65,1.28)\end{array}$ & 0.59 & & & $31(7.9 \%)$ & $67(10.0 \%)$ & $\begin{array}{c}1.09 \\
(0.94,1.27)\end{array}$ & 0.27 & & \\
\hline \multicolumn{13}{|l|}{ Gender-specific characteristics } \\
\hline Male partner is circumcised (physical exam) & $37(30.1 \%)$ & $329(34.3 \%)$ & $\begin{array}{c}1.02 \\
(0.98,1.07)\end{array}$ & 0.36 & & & $483(57.4 \%)$ & $760(53.2 \%)$ & $\begin{array}{c}0.94 \\
(0.88,1.00)\end{array}$ & 0.049 & $\begin{array}{c}0.94 \\
(0.88,1.00)\end{array}$ & 0.0614 \\
\hline $\begin{array}{l}\text { Female partner uses hormonal } \\
\text { contraceptives }\end{array}$ & $18(14.6 \%)$ & $157(16.3 \%)$ & $\begin{array}{c}1.01 \\
(0.96,1.07)\end{array}$ & 0.63 & & & $160(19.0 \%)$ & $279(19.5 \%)$ & $\begin{array}{c}1.01 \\
(0.93,1.10)\end{array}$ & 0.77 & & \\
\hline Female uses vaginal drying & $24(19.5 \%)$ & $196(20.4 \%)$ & $\begin{array}{c}1.01 \\
(0.95,1.06)\end{array}$ & 0.82 & & & $156(18.5 \%)$ & $322(22.5 \%)$ & $\begin{array}{c}1.09 \\
(1.01,1.18)\end{array}$ & 0.025 & $\begin{array}{c}1.08 \\
(1.00,1.17)\end{array}$ & 0.051 \\
\hline \multicolumn{13}{|l|}{ Couple characteristics $^{\ddagger}$} \\
\hline Couple is married & $94(76.4 \%)$ & $776(80.7 \%)$ & $\begin{array}{c}1.03 \\
(0.98,1.09) \\
\end{array}$ & 0.26 & & & $589(70.0 \%)$ & $1078(75.4 \%)$ & $\begin{array}{c}1.11 \\
(1.03,1.20) \\
\end{array}$ & 0.005 & & \\
\hline Duration of sexual relationship & $4(2-8)$ & $7(3-15)$ & $\begin{array}{c}1.06 \\
(1.04,1.09)^{\dagger}\end{array}$ & $<.001$ & & & $4(2-7)$ & $6(3-10)$ & $\begin{array}{c}1.18 \\
(1.13,1.24) \dagger\end{array}$ & $<.001$ & & \\
\hline
\end{tabular}


Table 1 Population characteristics and risk factors for HSV-2 seropositivity among HIV-1 uninfected members of African HIV-1 serodiscordant partnerships (Continued)

\begin{tabular}{|c|c|c|c|c|c|c|c|c|c|c|}
\hline Years living together & $3(1-6)$ & $6(3-13)$ & $\begin{array}{c}1.06 \\
(1.03,1.09)^{\dagger}\end{array}$ & $<.001$ & $3(1-6)$ & $5(2-10)$ & $\begin{array}{c}1.20 \\
(1.15,1.26) \dagger\end{array}$ & $<.001$ & $\begin{array}{c}1.07 \\
(1.02,1.13)\end{array}$ & 0.009 \\
\hline Number of children & $1(1-3)$ & $3(1-4)$ & $\begin{array}{c}1.03 \\
(1.02,1.04)\end{array}$ & $<.001$ & $2(1-3)$ & $2(1-4)$ & $\begin{array}{c}1.05 \\
(1.04,1.07)\end{array}$ & $<.001$ & $\begin{array}{c}1.02 \\
(1.01,1.04)\end{array}$ & 0.001 \\
\hline Informal housing & $50(41.3 \%)$ & $348(37.5 \%)$ & $\begin{array}{c}0.98 \\
(0.94,1.03)\end{array}$ & 0.41 & $346(42.5 \%)$ & $540(38.9 \%)$ & $\begin{array}{c}0.95 \\
(0.89,1.01)\end{array}$ & 0.099 & & \\
\hline $\begin{array}{l}\text { Number of sex acts with study part-ner in } \\
\text { previous month (median, IQR) }\end{array}$ & $3(2-7)$ & $4(2-8)$ & $\begin{array}{c}1.02 \\
(0.99,1.05) \dagger\end{array}$ & 0.26 & $4(2-8)$ & $4(2-8)$ & $\begin{array}{c}0.96 \\
(0.92,1.01)^{\dagger}\end{array}$ & 0.13 & & \\
\hline $\begin{array}{l}\text { Any sex acts with partner in previous } \\
\text { month }\end{array}$ & $114(92.7 \%)$ & $885(92.1 \%)$ & $\begin{array}{c}0.99 \\
(0.92,1.07)\end{array}$ & 0.82 & $796(94.6 \%)$ & $1342(93.9 \%)$ & $\begin{array}{c}0.95 \\
(0.83,1.09)\end{array}$ & 0.47 & & \\
\hline $\begin{array}{l}\text { Any unprotected sex with study partner in } \\
\text { previous month }\end{array}$ & $32(26.0 \%)$ & $259(27.0 \%)$ & $\begin{array}{c}1.01 \\
(0.96,1.05) \\
\end{array}$ & 0.83 & $245(29.1 \%)$ & $451(31.6 \%)$ & $\begin{array}{c}1.04 \\
(0.97,1.12) \\
\end{array}$ & 0.23 & & \\
\hline $\begin{array}{l}\text { Enrollment site in Eastern (vs. southern) } \\
\text { Africa }\end{array}$ & $78(63.4 \%)$ & $593(61.7 \%)$ & $\begin{array}{c}0.99 \\
(0.95,1.04)\end{array}$ & 0.71 & $509(60.5 \%)$ & $874(61.2 \%)$ & $\begin{array}{c}1.01 \\
(0.95,1.08)\end{array}$ & 0.76 & & \\
\hline
\end{tabular}

\# Multivariate risk ratios, adjusted for other factors in the model as shown.

* Risk ratio of HSV2 positivity for every 100 ct increase in CD4.

+ Risk ratio of HSV2 positivity for every increase of 10

₹ As reported by HIV-1 uninfected participant.

(Note: Length of sexual relationship strongly associated with age of partner, rho $=0.66, \mathrm{p}<.0001$.)

! Years of education was not a significant risk factor for HSV-2 seropositivity in male HIV-1 uninfected partners 


\section{Discussion}

In this multi-national study of 3354 African HIV-1 serodiscordant couples in which one partner was duallyinfected with HIV-1 and HSV-2, HIV-1 plasma RNA and CD4 count of the HIV-1 infected partner were not significantly associated with HSV-2 infection concordance in the HIV-1 uninfected partner. Furthermore, despite a recent prospective clinical trial reporting association of male circumcision with reduced HSV-2 acquisition [13], male circumcision in male HIV-1 uninfected partner was only marginally protective against HSV-2 infection in our cross-sectional multivariate analysis.

Prevalence of HSV-2 in the HIV-1 uninfected partner was high in our study (63\% in men and $89 \%$ in women) compared to other African cohorts [14,15], possibly due to the high rate of HSV-2 transmission reported in stable, long-term partnerships [16,17]. Also consistent with other studies [18-20], HSV-2 infection at enrollment in the HIV-1 uninfected partner was significantly associated with older age and was higher among women compared to men. The former may indicate that age is a surrogate for duration of sexual exposure in these couples [21].

A limitation of this cross-sectional study was the inability to determine temporal relationships of HIV-1 and HSV-2 infection in the dually-infected partner or recency of HSV-2 infection in the HIV-uninfected partners, thus limiting our analysis of behavioral correlates with HSV-2 infection. HSV-2 concordance may reflect HSV-2 transmission within the couple or acquisition outside the partnership. Our study eligibility criteria included that couples be sexually active and intend to remain together; as such we may have selected for older, more stable couples.

\section{Conclusions}

In summary, among African HIV-1 serodiscordant couples in which all the HIV-infected partners were dually infected with HSV-2, 71\% of their HIV-1 uninfected partners had HSV-2 infection, and HSV-2 infection in the HIV-uninfected partner was not associated with HIV-1 plasma RNA and CD4 count in the HIV-infected partner, or male circumcision in the HIV-1 uninfected partner. Given the need to identify interventions to reduce HSV-2 transmission, future research should focus on prospective analysis of risk factors for HSV-2 transmission, which will be conducted in this cohort.

\section{Acknowledgements}

We are grateful to the study participants for their participation and dedication. We thank the study team members at the research sites and at the University of Washington for their contributions to study implementation and data collection. This study was supported through a research grant from the Bill \& Melinda Gates Foundation (grant ID \# 26469)
Partners in Prevention HSV/HIV Transmission Study Team: University of Washington Coordinating Center and Central Laboratories Seattle, USA: Connie Celum (principal investigator), Anna Wald (protocol cochair), Jairam Lingappa (medical director), Jared M. Baeten, Mary Campbell, Lawrence Corey, Robert W. Coombs, James P. Hughes, Amalia Magaret, M. Juliana McElrath, Rhoda Morrow, James I. Mullins

\section{Study sites and site principal investigators}

Cape Town, South Africa (University of Cape Town): David Coetzee; Eldoret, Kenya (Moi University, Indiana University): Kenneth Fife, Edwin Were; Gaborone, Botswana (Botswana Harvard Partnership): Max Essex, Joseph Makhema; Kampala, Uganda (Infectious Disease Institute, Makerere University): Elly Katabira, Allan Ronald; Kigali, Rwanda (Rwanda Zambia HIV Research Group, and Emory University): Susan Allen, Kayitesi Kayitenkore, Etienne Karita; Kisumu, Kenya (Kenya Medical Research Institute, University of California San Francisco): Elizabeth Bukusi, Craig Cohen; Kitwe, Zambia (Rwanda Zambia HIV Research Group, and Emory University): Susan Allen, William Kanweka; Lusaka, Zambia (Rwanda Zambia HIV Research Group, and Emory University): Susan Allen, Bellington Vwalika; Moshi, Tanzania (Kilimanjaro Christian Medical College, Harvard University): Saidi Kapiga, Rachel Manongi; Nairobi, Kenya (University of Nairobi, University of Washington): Carey Farquhar, Grace John-Stewart, James Kiarie; Ndola, Zambia (Rwanda Zambia HIV Research Group, and Emory University): Susan Allen, Mubiana Inambao; Orange Farm, South Africa (Reproductive Health Research Unit, University of the Witwatersrand): Sinead Delany-Moretlwe, Helen Rees; Soweto, South Africa (Perinatal HIV Research Unit, University of the Witwatersrand): Guy de Bruyn, Glenda Gray, James McIntyre; Thika, Kenya (University of Nairobi, University of Washington): Nelly Rwamba Mugo Data management was provided by DF/Net Research, Inc. (Seattle, USA) and site laboratory oversight was provided by Contract Lab Services (University of the Witwatersrand, Johannesburg, South Africa).

\section{Author details}

${ }^{1}$ Department of Global Health, University of Washington, Seattle, WA, USA. ${ }^{2}$ Department of Laboratory Medicine, University of Washington, Seattle, WA USA. ${ }^{3}$ Department of Medicine, University of Washington, Seattle, WA, USA. ${ }^{4}$ Department of Epidemiology, University of Washington, Seattle, WA, USA. ${ }^{5}$ Department of Pediatrics, University of Washington, Seattle, WA, USA.

\section{Authors' contributions}

AM wrote the first draft along with $J$ and JMB. ASM analyzed the data. All authors contributed to the gathering of data, interpretation of results, and writing of the manuscript, and all approved the final draft.

\section{Competing interests}

The authors declare that they have no competing interests.

Received: 1 March 2011 Accepted: 15 March 2011

Published: 15 March 2011

\section{References}

1. Looker KJ, Garnett GP, Schmid GP: An estimate of the global prevalence and incidence of herpes simplex virus type 2 infection. Bull World Health Organ 2008, 86(10):805-12, A.

2. Corey $L$, Wald A, Celum $C L$, et al: The Effects of Herpes Simplex Virus-2 on HIV-1 Acquisition and Transmission: A Review of Two Overlapping Epidemics. J Acquir Immune Defic Syndr 2004, 35(5):435-445.

3. Robinson NJ: Age-specific prevalence of infection with herpes simplex virus types 2 and 1: a global review. J Infect Dis 2002, 186(Suppl 1):S3-28.

4. Freeman EE, Weiss HA, Glynn JR, et al: Herpes simplex virus 2 infection increases HIV acquisition in men and women: systematic review and meta-analysis of longitudinal studies. AIDS 2006, 20(1):73-83.

5. Van de Perre $P$, Segondy $M$, Foulongne $V$, et al: Herpes simplex virus and HIV-1: deciphering viral synergy. Lancet Infect Dis 2008, 8(8):490-7.

6. Dunkle KL, Stephenson R, Karita E, et al: New heterosexually transmitted HIV infections in married or cohabiting couples in urban Zambia and Rwanda: an analysis of survey and clinical data. Lancet 2008, 371(9631):2183-91

7. Lingappa JR, Lambdin B, Bukusi EA, et al: Regional Differences in Prevalence of HIV-1 Discordance in Africa and Enrollment of HIV-1 Discordant Couples into an HIV-1 Prevention Trial. PLOS ONE 2008, 3(1): e1411. 
8. Laeyendecker O, Henson C, Gray RH, et al: Performance of a commercial, type-specific enzyme-linked immunosorbent assay for detection of herpes simplex virus type 2-specific antibodies in Ugandans. J Clin Microbiol 2004, 42(4):1794-6.

9. Gamiel JL, Tobian AA, Laeyendecker OB, et al: Improved performance of enzyme-linked immunosorbent assays and the effect of human immunodeficiency virus coinfection on the serologic detection of herpes simplex virus type 2 in Rakai, Uganda. Clin Vaccine Immunol 2008, 15(5):888-90.

10. Golden MR, Ashley-Morrow R, Swenson P, et al: Herpes simplex virus type 2 (HSV-2) Western blot confirmatory testing among men testing positive for HSV-2 using the focus enzyme-linked immunosorbent assay in a sexually transmitted disease clinic. Sex Transm Dis 2005, 32(12):771-7.

11. Celum C, Wald A, Lingappa JR, et al: Acyclovir and Transmission of HIV-1 from Persons Infected with HIV-1 and HSV-2. N Engl J Med 2010, 362(5):427-439.

12. Schacker TW, Zeh JE, Hu H, et al: Changes in plasma human immunodeficiency virus type 1 RNA associated with herpes simplex virus reactivation and suppression. $J$ Infect Dis 2002, 186(12):1718-1725.

13. Tobian AA, Serwadda D, Quinn TC, et al: Male circumcision for the prevention of HSV-2 and HPV infections and syphilis. N Engl J Med 2009, 360(13):1298-309.

14. Tobian AA, Charvat B, Ssempijja V, et al: Factors Associated with the Prevalence and Incidence of Herpes Simplex Virus Type 2 Infection among Men in Rakai, Uganda. J Infect Dis 2009.

15. Freeman EE, Glynn JR: Factors affecting HIV concordancy in married couples in four African cities. AIDS 2004, 18(12):1715-21.

16. Halton $K$, Ratcliffe $A A$, Morison $L$, et al: Herpes simplex 2 risk among women in a polygynous setting in rural West Africa. AIDS 2003, 17(1):97-103.

17. Allen S, Meinzen-Derr J, Kautzman M, et al: Sexual behavior of HIV discordant couples after HIV counseling and testing. AIDS 2003, 17(5):733-40.

18. Kebede $Y$, Dorigo-Zetsma W, Mengistu Y, et al: Transmission of Herpes Simplex Virus Type 2 among factory workers in Ethiopia. J Infect Dis 2004, 190(2):365-72.

19. Mertz GJ, Benedetti J, Ashley R, et al: Risk factors for the sexual transmission of genital herpes. Ann Intern Med 1992, 116:197-202.

20. Weiss $\mathrm{H}$ : Epidemiology of herpes simplex virus type 2 infection in the developing world. Herpes 2004, 11(Suppl 1):24A-35A.

21. Wald A: Herpes simplex virus type 2 transmission: risk factors and virus shedding. Herpes 2004, 11(Suppl 3):130A-137A.

doi:10.1186/1756-0500-4-64

Cite this article as: Mujugira et al:: Risk Factors for HSV-2 Infection among Sexual Partners of HSV-2/HIV-1 Co-Infected Persons. BMC Research Notes 2011 4:64.

\section{Submit your next manuscript to BioMed Central and take full advantage of:}

- Convenient online submission

- Thorough peer review

- No space constraints or color figure charges

- Immediate publication on acceptance

- Inclusion in PubMed, CAS, Scopus and Google Scholar

- Research which is freely available for redistribution 